\title{
Z R Research Square \\ Comparison of local infiltration anesthesia and mucous surface anesthesia in trans-rectal ultrasound-guided prostate biopsy
}

\section{Sijie Lin}

Third Affiliated Hospital of Sun Yat-Sen University

\section{Zhijun Zang}

Third Affiliated Hospital of Sun Yat-Sen University

Minhua Lu

Third Affiliated Hospital of Sun Yat-Sen University

Jieying Wu

Third Affiliated Hospital of Sun Yat-Sen University

Xinghao Li

Third Affiliated Hospital of Sun Yat-Sen University

Youqiang Fang (D Fang_1573@126.com )

Third Affiliated Hospital of Sun Yat-Sen University https://orcid.org/0000-0001-7814-4889

Research article

Keywords: Local infiltration anesthesia, Mucous surface anesthesia, Trans-rectal ultrasound-guided, Prostate biopsy, Randomized controlled trial

Posted Date: June 4th, 2019

DOI: https://doi.org/10.21203/rs.2.9752/v1

License: (c) (i) This work is licensed under a Creative Commons Attribution 4.0 International License. Read Full License 


\section{Abstract}

Background: To compare the efficacy and safety of local infiltration anesthesia and mucous surface anesthesia in patients undergoing trans-rectal ultrasound-guided (TRUS guided) prostate biopsy. Methods: Patients with suspected prostate cancer undergoing TRUS guided prostate biopsy were randomly divided into two groups between January 2018 and March 2019. Local infiltration anesthesia was performed in the experimental group with lidocaine; while the control group was treated with mucous surface anesthesia. We collected baseline characteristics. Residual urine volume was measured twice: before biopsy, the first micturition after biopsy. Associated complications, positive rate of biopsy, visual analog pain scale (VAS) and Gleason score were recorded. Results: The study included 78 patients. The pain score of experimental group was significantly lower than the control group. Experimental group had lower rate of urinary retention and catheterization. Both groups had similar positive rate of biopsy, residual urine volume, Gleason score, fever and so on. Conclusion: Comparing with mucous surface anesthesia, local infiltration anesthesia relieved the pain better in patients undergoing TRUS guided prostate biopsy. It was more effective and safer. Trial registration: Chinese Clinical Trial Registry, Trial registration number (TRN): ChiCTR1800016424, Date of registration: 01/06/ 2018.

\section{Background}

Prostate biopsy is the gold standard for diagnosing prostate cancer[1]. TRUS guided prostate biopsy has the advantages of low cost, no radiation and accuracy[2]. Local infiltration is currently the most commonly used anesthesia method in the world, including lumbar infiltration anesthesia, perineal infiltration anesthesia and trans-rectal infiltration anesthesia. Trans-rectal infiltration anesthesia is the standard for prostate puncture due to minimal invasion, good effect, and cost-effectiveness[3]. However, the ideal location, type and number of trans-rectal infiltration anesthesia are unclear. There is no uniform standard for its clinical application[4]. Poor anesthesia can lead to pain and discomfort during biopsy. Anal contraction or lower extremity twitching can cause displacement and inaccuracy of puncture. For elderly patients, severe cases may cause cardiovascular adverse events[5ヌ6]. Poor anesthesia may increase the incidence of complications, hinder the process of puncture and even affect the quality of prostate specimen. Whether trans-rectal infiltration anesthesia can affect the accuracy of puncture, the degree of pain and the incidence of biopsy complications? Theses questions lack clear research evidence. Mucous surface anesthesia is easy to perform and can be applied without ultrasound. To compare the two ways of anesthesia, we conducted this prospective randomized controlled trial.

\section{Methods}

After obtaining patient consent, 78 patients scheduled for prostate biopsy were included in the study. A sample size was calculated based on the incidence of prostate cancer in Guangzhou and the number of inpatients with prostate cancer in our hospital.

\section{Basic information}

Patients who underwent trans-rectal ultrasound-guided prostate biopsy in the Third Affiliated Hospital of Sun Yat-sen University were included in the study. Inclusion criteria: 1. Digital rectal examination revealed any suspicious nodules. 2. Prostate specific antigen (PSA) $>10 \mathrm{ng} / \mathrm{ml}$, any $\mathrm{f} / \mathrm{t}$ PSA and PSAD (PSA density) values. 3. PSA 4-10ng/ml, $\mathrm{f} / \mathrm{t}$ PSA abnormality or abnormal PSAD value. 4. PSA 4-10ng/ml, f/t PSA and PSAD values were normal, B-ultrasound found abnormal echo nodules or abnormal MRI signals[7ه8]. Exclusion criteria: The study excluded patients with history of previous prostate biopsy, chronic prostatitis, pelvic pain syndrome, bleeding diathesis, persistent urinary tract infection (UTI), anal surgery, concomitant analgesic medication or any other state that could potentially interfere our assessment of pain.

Biopsy steps and indicators

Prostate volume was obtained assisted by three dimensional measurements computed by MRI calculation. PSA and f-PSA were determined before puncture. Antibiotic prophylaxis was given to these patients (oral metronidazole and levofloxacin 1 day before puncture). Cleansing enema were administered on the evening before biopsy and on the morning of biopsy. Residual urine 
volume was determined before biopsy and the first micturation after biopsy with the help of ultrasound. Patients were randomized into two groups using a random number table. The randomization schedule was generated by an independent investigator through a random number table. Another two doctors enrolled participants and assigned body sites to interventions separately. The study protocol was explained to patients, and information was provided about the VAS. In the experimental group, $2 \%$ lidocaine guided by color Doppler ultrasound infiltrated the vascular nerve bundle around the angle between the bilateral prostate base and the seminal vesicle, $5 \mathrm{ml}$ on each side. Patients in the control group were anesthetized around the mucous surface with $10 \mathrm{ml}$ lidocaine gel[$[9,10]$. All patients did not know the anesthesia method used for their puncture. Puncture location was guided by a specific B-ultrasound doctor who specialized in prostate biopsy. The puncture was performed by the same doctor with stable technique. Associated data was obtained by another doctor separately. Liquid gel was applied to the probe to reduce discomfort. In consideration of the filing degree of bladder may cause discomfort and increase the risk of puncture, patients were asked to empty their bladders before biopsy. Usually, twelve cores biopsies were suggested, 6 for each lobe of the prostate ( 3 for left and right peripheral zone, 1 for left and right transitional zone, 2 for left and right central zone). We adjusted the number of cores according to morphological description of potential pathological features. Patients were asked to grade from 0 to 10 with 0 denoting absence of discomfort, 1-3 mild, 4-6 moderate, and 7-10 severe in the 10-point VAS after biopsy[11, 12].

Statistical methods

Data analysis was done by SPSS 20 software. Normal distribution data was represented by the mean $\pm S D$, and the mean was compared by the independent sample t test. Non-normal distribution data were expressed as median and inter-quartile range, and the median was compared by the Mann-Whitney test. The count data was compared using a chi-square test. A p value of less than 0.05 was considered statistically significant(Fig. 1区2).

\section{Results}

Baseline characteristic

78 patients were recruited during January 2018 and March 2019, 39 in Group1 and 39 in Group2. The two groups were evenly matched. There was no significant difference among the two groups in terms of demographic data (Table 1 ).

Major research indicators

The pain score of the experimental group after puncture was significantly lower than the control group. There was no statistical difference in residual urine volume between the two groups (Table 2 ).

Complications and positive rate of biopsy

There was no difference in positive rate of biopsy between the two groups. Most of them are self-limiting[13]. The experimental group had lower rate of urinary retention and catheterization. No significant difference was seen in other complications (Table 3 ).

\section{Discussion}

Prostate cancer is the most common cancer among men in the world[14, 15]. To improve cancer detection rate, needle aspiration of 12 or more needles is recommended for clinical use to obtain the maximum cancer detection rate and avoid repeated puncture $[16,17]$. However, the increase of needles brings discomfort such as pain and anxiety. Local infiltration anesthesia, topical anesthesia and intravenous anesthesia are used for prostate biopsy[18]. To be effective, local anesthesia anaesthesia should block all possible routes of painful stimuli. One region requiring blockade is the prostatic sac which has rich autonomic innervation conveying visceral pain to the spinal cord via fibers that run with the vascular pedicles basolaterally[19]. Without local infiltration anesthesia, most patients cannot stand puncture again. With the administration of local infiltration anesthesia, patients describe the perception of pain similar to pinching of skin with fingers softly.

Factors like benign prostatic hyperplasia, enlargement of prostate, and bladder outlet obstruction are responsible for lower urinary tract symptoms[20]. Residual urine volume is a good indicator to assess the risk of urinary retention. No difference was found in 
residual urine volume between the two groups which indicated that pain was not a primary risk factor for the increase of residual urine volume. Some patients failed to urinate and had to be catheterized even though they had defecated. Therefore the gauze inside the anus is possibly not a influence factor for the increase of residual urine volume. The increase of residual urine volume is very complicated. Acute inflammation reaction induced by inflammatory factors is related to it. The pathway of inflammation reaction may vary among patients.

All patients included completed the biopsy process. Perineal puncture is a better choice for sampling of the anterior and apical regions, especially when the prostate is large[21]. However, combination of both tans-rectal and perineal puncture could not improve cancer detection rate compared to tans-rectal solely[22].

Gross hematuria and gross blood stool are common complications of prostate biopsy, but are generally self-limiting[24]. Infection is a serious adverse event of prostate biopsy with an increasing incidence [25]. Trans-rectal biopsy has an increasing rate of infection because of increasing multi-drug resistant rectal flora compared with perineal biopsy[26]. Perineal biopsy was rarely associated with infection but more commonly with urinary retention[27].

One of the inadequacy of our study is that only 70 patients were included in this trial. Besides, sub-group analysis was not performed as the subsamples of different age group were relatively small. Our results only applied to prostate cancer without distant metastasis.

\section{Conclusion}

In short, local infiltration anesthesia was more effective and safer than mucous surface anesthesia. It should be recommended for TRUS guided prostate biopsy.

\section{Abbreviations}

TRUS guided: Trans-rectal ultrasound-guided

VAS: Visual analog pain scale

PSA: Prostate specific antigen

UTI: Urinary tract infection

ChiCTR: Chinese Clinical Trial Registry

PSA: Prostate specific antigen

\section{Declarations}

\section{Ethics approval and consent to participate}

Ethical approval for this randomized-controlled study was provided by the Ethics Committee of The Third Affiliated Hospital of Sun Yat-sen University, Guangzhou, China. The study was registered on Chinese Clinical Trial Registry (ChiCTR) with the registration number ChiCTR1800016424. We obtained the written consent from the participants. All the procedures we carry out in our studies involving human participants are consistent with the ethical standards of institutions and/or national research councils, as well as with the 1964 Helsinki Declaration and its subsequent amendments or similar ethical standards.

\section{Consent for publication}

We obtained consent for publication from patients.

\section{Availability of data and material}

The datasets used and/or analysed during the current study are available from the corresponding author on reasonable request. 


\section{Competing interests}

The authors claim that they have no conflict of interest.

\section{Funding}

This work was supported by the Science and Technology Planning Project of Guangzhou (201704020052) and Guangdong Natural Science Foundation (2018A030313946). The funding agent plays no role in study design, data collection, or data analyses.

\section{Authors' Contributions}

All authors had read and approved the final submitted version. All authors have agreed both to be personally accountable for their own contributions and to ensure that questions related to the accuracy or integrity of any part of the work.

SJL: Manuscript writing, puncture of prostate

ZJZ: Collection of pictures and videos, design of randomization schedule

XHL: Data analysis

MHL: Ultrasound guidance during prostate biopsy

JYW: Data Collection, enrollment of patient

YQF: Project development, randomization

\section{Acknowledgements}

Not applicable.

\section{References}

1.Vitrani MA, Baumann M, Reversat D, Morel G, Moreau-Gaudry A, Mozer P, et al. Prostate biopsies assisted by comanipulated probe-holder: first in man. International Journal of Computer Assisted Radiology and Surgery. 2016; 11(6): 1153-1161.

2.Ismail MT, Gomella LG. Transrectal Prostate Biopsy. Urologic Clinics of North America. 2013; 40(4): 457-472.

3.Izol V, Soyupak B, Seydaoglu G, Aridogan IA, Tansug Z. Three different techniques for administering analgesia during transrectal ultrasound-guided prostate biopsy: a comparative study. Int Braz J Urol. 2012; 38(1): 122-8.

4.Anastasiadis A, Zapała L, Cordeiro E, Antoniewicz A, Dimitriadis G, De Reijke T. Complications of prostate biopsy. Expert Review of Anticancer Therapy. 2013; 13(7): 829-37.

5.Yan P, Wang XY, Huang W, Zhang Y. Local anesthesia for pain control during transrectal ultrasound-guided prostate biopsy: a systematic review and meta-analysis. J Pain Res. 2016; 11(9): 787-796.

6.Nazir B. Pain during Transrectal Ultrasound-Guided Prostate Biopsy and the Role of Periprostatic Nerve Block: What Radiologists Should Know. Korean J Radiol. 2014; 15(5): 543-53.

7.Rodrigues Â1, Freitas R, Nogueira-Silva P, Jerónimo C, Henrique R. Biopsy sampling and histopathological markers for diagnosis of prostate cancer. Expert Rev Anticancer Ther. 2014; 14(11): 1323-36.

8.Ukimura O, Coleman JA, de la Taille A, Emberton M, Epstein JI, Freedland SJ, et al. Contemporary role of systematic prostate biopsies: indications, techniques, and implications for patient care. Eur Urol. 2013; 63(2): 214-30. 
9.Trucchi A, De Nunzio C, Mariani S, Palleschi G, Miano L, Tubaro A ( Local Anesthesia Reduces Pain Associated with Transrectal Prostatic Biopsy. Urologia Internationalis. 2005; 74(3): 209-213.

10.Jones JS, Ulchaker JC, Nelson D, Kursh ED, Kitay R, Angie S, et al. Periprostatic local anesthesia eliminates pain of office-based transrectal prostate biopsy. Prostate Cancer Prostatic Dis. 2003; 6(1): 53-5.

11.Addla SK, Adeyoju AA, Wemyss-Holden GD, Neilson D. Local Anaesthetic for Transrectal Ultrasound-Guided Prostate Biopsy: A Prospective, Randomized, Double Blind, Placebo-Controlled Study. European Urology. 2003; 43(5): 441-443.

12.Gurbuz C, Canat L, Bayram G, Gokhan A, Samet G, Caskurlu T. Visual pain score during transrectal ultrasound-guided prostate biopsy using no anaesthesia or three different types of local anaesthetic application. Scandinavian Journal of Urology \& Nephrology. 2010; 44(4): 212-216.

13.Bennett HY, Roberts MJ, Doi SA, Gardiner RA. The global burden of major infectious complications following prostate biopsy. Epidemiol Infect. 2016; 144(8): 1784-91.

14. Baumgart SJ, Haendler B. Exploiting Epigenetic Alterations in Prostate Cancer. Int J Mol Sci. 2017; 18(5): E1017.

15. Giri VN1, Beebe-Dimmer JL. Familial prostate cancer. Semin Oncol. 2016; 43(5):560-565.

16. Bjurlin MA, Wysock JS, Taneja SS. Optimization of Prostate Biopsy: review of technique and complications. Urologic Clinics of North America. 2014; 41(2): 299-313.

17. Guo G, Xu Y, Zhang X. TRUS-guided transperineal prostate $12+X$ core biopsy with template for the diagnosis of prostate cancer. Oncol Lett. 2017; 13(6): 4863-4867.

18.Lee C, Woo HH. Current methods of analgesia for transrectal ultrasonography (TRUS)-guided prostate biopsy - a systematic review. BJU International. 2014; 113 (Supplement S2): 48-56.

19. Berger AP, Frauscher F, Halpern EJ, Spranger R, Steiner H, Bartsch G, et al. Periprostatic administration of local anesthesia during transrectal ultrasound-guided biopsy of the prostate: a randomized, double-blind, placebo-controlled study. Urology. 2003; 61(3): 585-588.

20. Bushman WA, Jerde TJ. The role of prostate inflammation and fibrosis in lower urinary tract symptoms. American Journal of Physiology-Renal Physiology. 2016; 311(4): F817-F821.

21. Eldred-Evans D, Kasivisvanathan V, Khan F, Hemelrijck MV, Polson A, Acher P, et al. The Use of Transperineal Sector Biopsy as A First-Line Biopsy Strategy: A Multi-Institutional Analysis of Clinical Outcomes and Complications. Urol J. 2016; 13(5): 28492855.

22. Shida Y, Hakariya T, Takehara K, Onita T, Miyata Y, Sakai H. Comparison Between a Combined Transrectal and Transperineal Approach and a Transrectal Approach for Prostate Rebiopsy. Anticancer Research. 2016; 36(9): 4685-4690.

23. Bulbul MA, Haddad MC, Khauli RB, Hemady K, Shaar A, Khouzami R, et al. Periprostatic infiltration with local anesthesia during transrectal ultrasound-guided prostate biopsy is safe, simple, and effective: a pilot study. Clin Imaging. 2002; 26(2): 12932.

24.Wagenlehner FM, van Oostrum E, Tenke P, Tandogdu Z, Çek M, Grabe M, et al. Infective Complications After Prostate Biopsy: Outcome of the Global Prevalence Study of Infections in Urology (GPIU) 2010 and 2011, A Prospective Multinational Multicentre Prostate Biopsy Study. European Urology. 2013; 63(3): 521-527.

25. Grummet J. How to Biopsy : Transperineal Versus Transrectal, Saturation Versus Targeted, What's the Evidence? Urologic Clinics of North America. 2017; 44(4): 525-534. 
26. Skouteris VM, Crawford ED, Mouraviev V, Arangua P, Metsinis MP, Skouteris M, et al. Transrectal Ultrasound-guided Versus Transperineal Mapping Prostate Biopsy: Complication Comparison. Rev Urol. 2018; 20(1): 19-25.

27.Kalkanlı A, Gezmiş CT, Özkan A, Çilesiz NC, Yanaral F, Aydın M, et al. Comparison of Single \& Prolonged Fluoroquinolone Prophylaxis and Risk Factors for Infectious Complications After Transrectal Prostate Biopsy. Balkan Medical Journal. 2018; 35(5): 373-377.

\section{Tables}

Table1 Basic characteristic

\begin{tabular}{|c|c|c|c|c|c|c|c|c|c|}
\hline & $\mathrm{n}$ & $\begin{array}{l}\text { Age } ₫ \text { year》 } \\
(x \pm s \rrbracket\end{array}$ & $\begin{array}{l}\text { t-PSA } \\
(\mathrm{ng} / \mathrm{ml})\end{array}$ & $\begin{array}{l}\text { f-PSA } \\
\text { (ng/ml) }\end{array}$ & $\begin{array}{l}\text { Prostate } \\
\text { volume } \\
\text { (ml) }\end{array}$ & IPSS『n』 & Core\n』 & $\begin{array}{l}\text { Catheterizasion } \\
\text { before biopsy } \\
\text { 『nヌ }\end{array}$ & $\begin{array}{l}\text { High } \\
\text { urine } \\
\text { WBC『n』 }\end{array}$ \\
\hline $\begin{array}{l}\text { Experime- } \\
\text { ntal } \\
\text { group }\end{array}$ & 39 & $67.38 \pm 7.29$ & 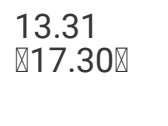 & $\begin{array}{l}2.21 \\
\otimes 3.08 \bigotimes\end{array}$ & $56 \rrbracket 58 \rrbracket$ & $14.67 \pm 6.00$ & 12Х1ه & 12 & 9 \\
\hline $\begin{array}{l}\text { Control } \\
\text { group }\end{array}$ & 39 & $68.44 \pm 8.68$ & 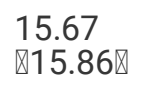 & $\begin{array}{l}2.30 \\
\nabla 3.42 \rrbracket\end{array}$ & $63 \rrbracket 52 \rrbracket$ & $14.82 \pm 7.71$ & 12ه1ه & 13 & 12 \\
\hline Statistics & & $t=-0.579$ & $Z=-0.345$ & $Z=-0.045$ & $Z=-0.710$ & $t=-0.098$ & $Z=-0.724$ & $(2=0.059$ & $(2=0.586$ \\
\hline$P$ value & & 0.564 & 0.730 & 0.964 & 0.478 & 0.922 & 0.469 & 0.808 & 0.444 \\
\hline
\end{tabular}

Abbreviation: t-PSA=total prostate specific antigen; f-PSA=free prostate specific antigen; IPSS=Internation prostate symptom score; WBC=White blood cell.

Table2 VAS and residual urine volume

\begin{tabular}{|c|c|c|c|c|c|}
\hline & $\mathrm{n}$ & VAS $₫ n \rrbracket$ & RUV1ヌml区 & RUV2』mI $\rrbracket$ & RUV2-1邓ml区 \\
\hline Experime-ntal group & 39 & $3 \otimes 1 \rrbracket$ & $13.5 \rrbracket 27.5 \rrbracket$ & 80囚163】 & $55.5 \rrbracket 133.5 \rrbracket$ \\
\hline Control group & 39 & $6 \llbracket 1 \rrbracket$ & $31.5 \rrbracket 43.25 \rrbracket$ & 107ه112.75】 & $79.5 \otimes 90.25 \rrbracket$ \\
\hline$Z$ value & & -7.001 & -1.228 & -0.788 & -0.723 \\
\hline$P$ value & & $\nabla 0.000$ & 0.220 & 0.431 & 0.470 \\
\hline
\end{tabular}

Abbreviation: VAS=visual analog pain scale; RUV1=residual urine volume before puncture; RUV2=residual urine volume after puncture; RUV2-1=Difference of residual urine before and after puncture.

Table3 Biopsy positive rate and complication

\begin{tabular}{|c|c|c|c|c|c|c|c|}
\hline & $\mathrm{n}$ & $\begin{array}{l}\text { Positive } \\
\text { biopsy } \llbracket n \rrbracket\end{array}$ & $\begin{array}{l}\text { Gleason } \\
\text { score(n ) }\end{array}$ & $\begin{array}{l}\text { Gross } \\
\text { hematuria } \mathbb{n} \rrbracket\end{array}$ & $\begin{array}{l}\text { Gross bloody } \\
\text { stool } \mathbb{n} \rrbracket\end{array}$ & $\begin{array}{l}\text { Urinary } \\
\text { retention } \rrbracket n \rrbracket\end{array}$ & $\begin{array}{l}\text { Fever } \\
\text { \n囚 }\end{array}$ \\
\hline $\begin{array}{l}\text { Experime-ntal } \\
\text { group }\end{array}$ & 39 & 11 & $8(1)$ & 26 & 13 & 12 & 0 \\
\hline Control group & 39 & 11 & $8(2)$ & 23 & 11 & 15 & 0 \\
\hline Statistics & & $(2 \varangle 0.001$ & $Z=-0.080$ & $(2=0.494$ & $(2=0.241$ & $(2=0.510$ & - \\
\hline$P$ value & & 1.000 & 0.936 & 0.482 & 0.624 & 0.475 & - \\
\hline
\end{tabular}

Figures 

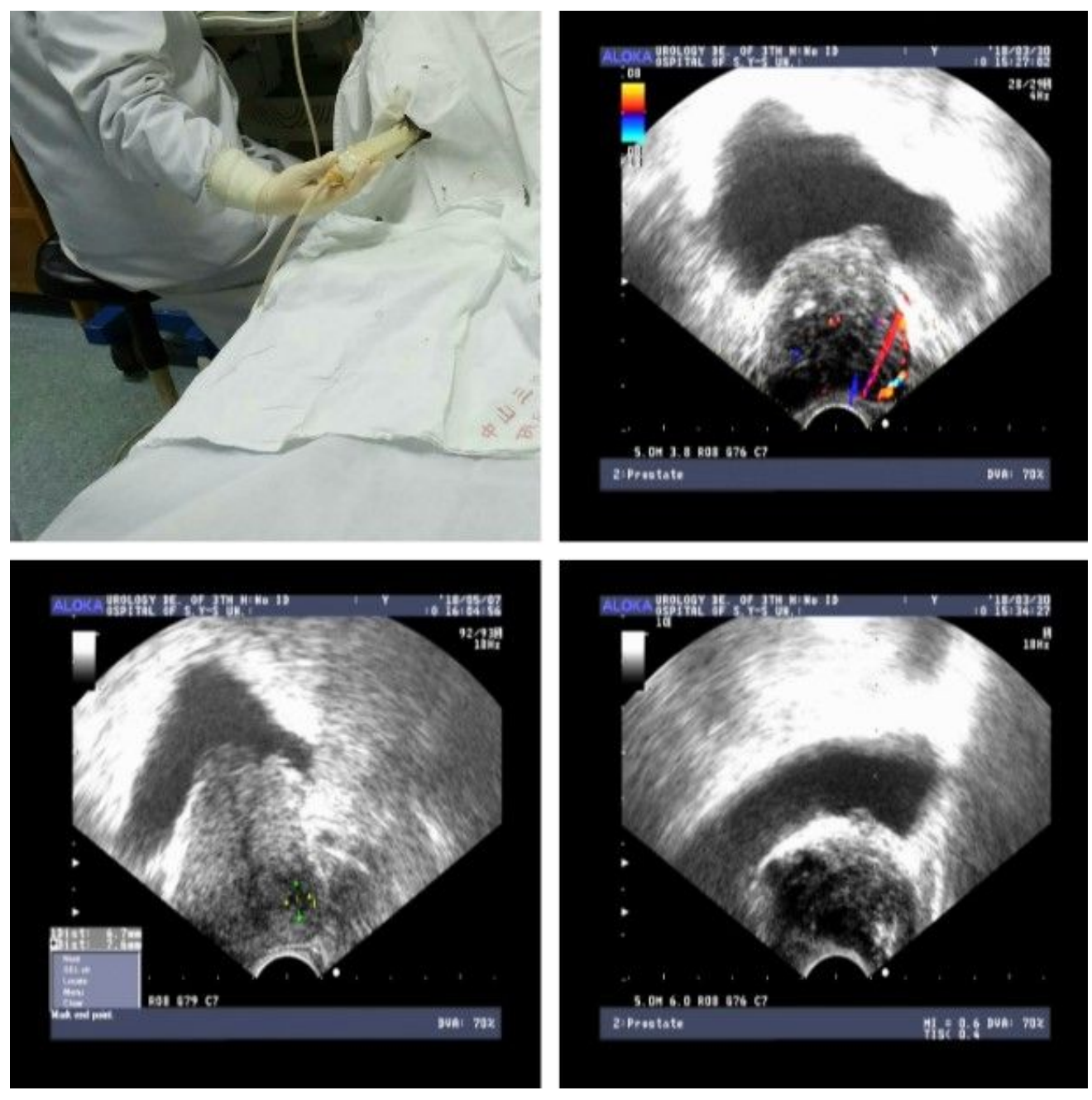

Figure 1

Trans-rectal ultrasound examination of prostate cancer. A) Puncture location was guided by a B-ultrasound doctor specialized in TRUS guided prostate biopsy B) Abnormal blood flow enrichment area of prostate C) Low echo zone of prostate D) Calcification of prostate. 

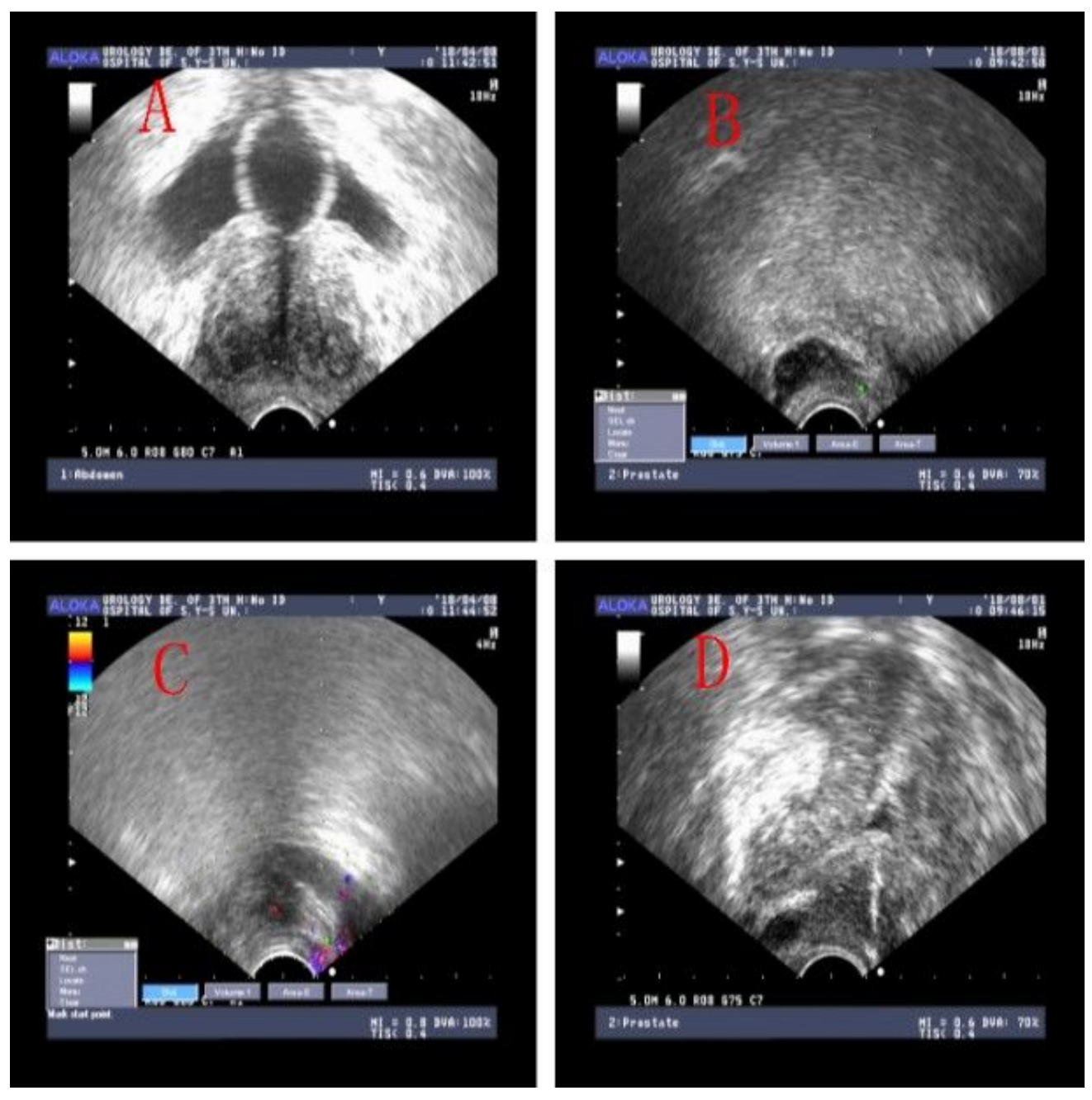

\section{Figure 2}

Local infiltration anesthesia. A) Large prostate with catheter B) Ultrasound located around the angle between the prostate base and the seminal vesicle C) Vascular nerve bundle inside the fat pad of prostate D) Sample of prostate.

\section{Supplementary Files}

This is a list of supplementary files associated with this preprint. Click to download.

- supplement1.docx 